\title{
Adaptation Study of Released Finger Millet (Eleusine Coracana L.) Varieties in Western Oromia, Ethiopia
}

\author{
Geleta Negash* \\ Department of Plant breeding and genetics \\ Oromia Agricultural Research Institute (IQQO), Haro Sabu Agricultural Research Center (HSARC), \\ P.0.Box 10, Kellem Wollega, Dembi Dollo, Ethiopia \\ Wakgari Raga \\ Agronomy \\ Oromia Agricultural Research Institute (IQQO), Haro Sabu Agricultural Research Center (HSARC), \\ P.0.Box 10, Kellem Wollega, Dembi Dollo, Ethiopia \\ Biru Alemu \\ Applied genetics \\ Oromia Agricultural Research Institute (IQQO), Haro Sabu Agricultural Research Center (HSARC), \\ P.0.Box 10, Kellem Wollega, Dembi Dollo, Ethiopia
}

\begin{abstract}
The experiment was conducted on eight improved finger millet varieties against local check at Chanka research sub site and on station at Haro Sabu Agricultural Research Center (HSARC) for two consecutive (2017-2018) years to identify and recommend high yielding, insect pest tolerant, and stable varieties. The seeds were planted in Randomized Completed Block Design (RCBD) with three replications in the net plot size of $3 \mathrm{~m}^{2}$ using four harvestable rows at the spacing of $30 \mathrm{~cm}$. Agronomic traits Viz. Days to heading (DH), Days to maturity (DM), Lodging percentage (LDG), Grain yield (GY), Plant height (PH), Finger length (FL), Productive tillers (PTR), Finger per main ear (FPME) Finger weight per plant (FWPP) and Head blast (HB) were collected and analyzed. Analysis of variance revealed significant difference among varieties for most observed traits. The combine ANOVA and the AMMI analysis for grain yield across environments revealed significantly affected by environments, that hold $40.84 \%$ of the total variation. The genotype and genotype by environmental interation were significant and accounted for $32.67 \%$ and $23.44 \%$ respectively. Pricipal component 1 and 2 accounted for $17.98 \%$ and $5.09 \%$ of the GEI respectively with a total of $23.07 \%$ variation.In general, Adis-01 and Boneya varieties were identified as the best varieties for yielding ability, stability, tolerant to diseases and recommended in the area and with similar agro-ecologies.
\end{abstract}

Keywords: Adaptability, finger millet (Eleusine coracana L.) stability varieties

DOI: $10.7176 / \mathrm{JBAH} / 9-11-09$

Publication date:June $30^{\text {th }} 2019$

\section{INTRODUCTION}

Finger millet,(Eleusine coracana L.) Gaertn. ssp. coracana), is the second most widely grown millets on the continent of Africa and it is an important crop grown in low input farming systems by resource poor farmers in eastern and southern Africa (Damar et al., 2016). This is indigenous to the highlands of Uganda and Ethiopia. Finger millet is widely produced by small scale landholders and consumed locally (Adugna et al., 2011). It is well adapted to heat, drought and poor soil stress that succeed in marginal and degraded soils (Okalebo, 1991). It is valued for nutrition, malt, good storability, income and other uses for animal feeds. In Ethiopia, finger millet covered 456171.54 hectare of land with the productivity of $22.30 \mathrm{qt} / \mathrm{ha}$ (CSA, 2017). However, low in yielding due to lack of high yielding cultivars, moisture stress, and lodging effect, diseases and low fertility and poor crop management practices (Degu et al., 2009). Strengthen the seed production and delivery systems for improved varieties also the most bottleneck of the crop in the small scale farmers.

Climatic change also directed to reduce the productivity of many crops around the world. So that a considerable attention should be given to the effect of genotype $\mathrm{x}$ environment interaction in the plant breeding programs, the relative performance of cultivars for quantitative traits such as yield and the other characters, which influence yield, vary from an environment to another. Consequently, to develop a variety with high yielding ability and consistency over locations, high attention should be given to the importance of stability performance for the genotypes under different environments and their interactions.

The impacts of phenotypic variation principally based on the environmental situation and the genetic constitution of the varieties. Such variation is more complicated by the fact that not all genotypes respond in a similar way to change in the environment and no two environments are exactly the same. The genotype $x$ environment interaction results in genotype rank changes from one environment to another, a dissimilar in scale 
among environments, or a combination of these two situations.

It is imperative to detect specific genotypes adapted to or stable in environment(s), in that way succeeding quick genetic gain through screening of genotypes for high adaptation and stability under varying environmental conditions prior to release as a variety (Ariyo, 1989; Flores et al., 1998; Showemimo et al., 2000; Mustapha et al., 2001). While, most genotypes show fluctuating yields when grown in different environments or agro-climatic zones. This makes difficulties indicating the superiority of a specific variety. To tackle this challenge, multilocation yield trials are essential to identify adaptable high yielding cultivars and discover sites that best represent the target environment (Yan et al., 2000). Adaptability is the result of genotype, environment and genotype by environment interaction. That means the ability to perform at an acceptable level in a range of environments, stated to as general adaptability, and the ability to perform well only in appropriate environments, known as specific adaptability (Farshadfar and Sutka, 2006).

Combined analysis of variance can quantity GxE interactions and express the main effects however, does not explain the interaction effect (Yuksel et al., 2002; Worku et al., 2013). The main reason of additive main effects and multiplicative interactions (AMMI) is appropriate for agricultural research is that the ANOVA part of AMMI can separate the $G$ and $E$ main effects and the $G \times E$ interaction effects (Gauch et al., 2008). Besides, its greatest advantage is its ability to take out interaction Principal Component Axis (PCA) along which there is a maximum variation, thus indicated the number of components necessary to explain the pattern in the interaction residual (Girma, 1999). Additive Main Effect and Multiplicative Interaction model and genotype and genotype by environment interaction (GGE) bi-plot analysis are the most frequently used analytical and statistical tools to determine the pattern of genotypic responses across environments (Gauch and Zobel, 1996; Yan et al., 2000; Yuksel et al., 2002).

AMMI and GGE bi-plot (Gauch and Zobbel, 1996; Yan et al., 2000; Yuksel et al., 2002) for graphical display of data and Eberhart and Russell (1966) model are the most commonly used analytical and statistical tools to identify stable, high yielding and adaptable genotype(s) for wider and/or specific environments.

Therefore, the objective of the study was to evaluate, select and recommend high yielder, tolerant to diseases, more adapted and stable varieties.

\section{MATERIALS AND METHODS}

Description of locations: The experiment was conducted at two different rain fed locations in Kellem and west Wollega zones of Haro-sebu agricultural research center for two consecutive year on station and chanka sub-site in western Oromia, Ethiopia, during the 2017-2018 main cropping season, that represent the varying agro ecologies of the finger millet growing areas of the zones.

Experimental materials: Eight finger millet varieties including local check were evaluated; (Adis-01, Bareda, Boneya,Diga, Gudetu, Urji, Wama and local check)

Experimental design and management: Randomized completed block design (RCBD) with three replications was used in all locations. Each experimental plot had six rows of $2.5 \mathrm{~m}$ long and $30 \mathrm{~cm}$ apart with a plot area of $1.8 \mathrm{~m} \times 2.5 \mathrm{~m}$. Drill planting by hand was used with the same rate for all locations. Fertilizer was applied at a rate of 150 and $100 \mathrm{kgha}^{-1}$ Urea and DAP respectively. All $\mathrm{P}_{2} \mathrm{O}_{5}$ and half of $\mathrm{N}$ were applied during planting, while the rest half splits were applied at tillering stages. A seeding rate of $15 \mathrm{~kg} \mathrm{ha}^{-1}$ was used. All agronomic management was carried out accordingly. The data considered for analysis was from the candidates of the net plot, thus the four central harvestable rows. The harvested genotypes were sundried before being tested for moisture content where $12 \%$ was the preferred average moisture content using moisture tester. Grain yield data was then obtained by weighing the dried grain using a digital scale.

Data collection method: Plants were selected randomly before heading from each row (four harvestable rows) and tagged with thread and all the necessary plant based data were collected from these sampled plants. Plot basis: Days to heading (DH), Days to maturity (DM), Lodging percentage (LDG), Grain yield (GY), and Head blast (HB) was recorded as an economic important of finger millet diseases. Plant basis: Plant height (PH), Finger length (FL), Productive tillers (PTR), Finger per main ear (FPME) and Finger weight per plant (FWPP)

Statistical analysis: The collected data were organized and subjected to analyzed using SAS version 9.2 (SAS, 2008) computer software and additive main effect and multiplicative interaction (AMMI) analysis and GGE biplot analysis were performed using Gen Stat 15th edition statistical package (VSN International,2012)

\section{RESULTS AND DISCUSSIONS}

\section{Combined analysis of variance}

The mean square of analysis of variance (ANOVA) is presented in Table 1. Highly significant differences were detected among the main and the interaction effects $(\mathrm{P} \leq 0.01)$ for most of the parameters. The combined analysis of variance showed that significant differences were recorded across location for all parameters except head blast. Year*varieties effects were significant for most traits. Year*location *varieties were significant for most traits such as days to heading, days to maturity, Finger length, productive tillers, lodging and grain yield . 
Table 1: Combined Analysis of variance (ANOVA) for grain yield and yield related traits of finger millet varieties

\begin{tabular}{|c|c|c|c|c|c|c|c|c|c|c|c|}
\hline Source & DF & DH & DM & PH & FL & PTL & FPME & FW & HB & LDG & YLDkgha \\
\hline rep & 2 & $7.1 * *$ & 2.6 & 63.3 & 0.36 & $6.3 * *$ & 0.6 & 24.3 & 0.3 & 0.1 & 14471.49 \\
\hline vrt & 7 & $189.6 * *$ & $70.3 * *$ & $357.1 * *$ & 1.49 & $12.2 * *$ & $6.1 * *$ & $83.6 * *$ & $6.9 * *$ & $2.2 * *$ & $5989786.2 * *$ \\
\hline loc & 1 & $256.8 * *$ & $870 * *$ & $11194 * *$ & $142 * *$ & $5.5 * *$ & $109.4 * *$ & $1526^{* *}$ & 0.0 & $6.5^{* *}$ & $6490671.8 * *$ \\
\hline yr & 1 & $2849 * *$ & $1283 * *$ & $527.6^{*}$ & 0.29 & $401.9 * *$ & $4.4^{*}$ & $9532 * *$ & $2.3 * *$ & $6.5^{* *}$ & $44471991 * *$ \\
\hline vrt*loc & 7 & $7.5 * *$ & $11.7 * *$ & 75.2 & $2.49 * *$ & 1.2 & $2.3 *$ & 18.2 & 0.1 & 0.5 & $2098575.5 * *$ \\
\hline vrt*yr & 7 & $49.4 * *$ & $36.5 * *$ & 110.5 & $6.4 * *$ & $3.6^{*}$ & 1.0 & 44.9 & $0.6^{*}$ & $2.2 * *$ & $1470375.4 * *$ \\
\hline loc*yr & 1 & $25.0 * *$ & $2214 * *$ & $585.8 *$ & $249.5 * *$ & $230.5 * *$ & 1.9 & $1036^{* *}$ & 0.0 & 0.1 & $1451713 * *$ \\
\hline vrt*loc*yr & 7 & $9.5 * *$ & $23.2 * *$ & 78.2 & $3.98 * *$ & $5.1 * *$ & 0.38 & 4.1 & 0.1 & $0.7^{*}$ & $729102.9 * *$ \\
\hline
\end{tabular}

Key: $* * *$, significant at $5 \%$ and $1 \%$ respectively, Loc $*$ vrt $=$ location by variety, Yr*Loc*vrt $=$ year by location by variety, DF -degree of freedom, DH- Days to Heading; DM- Days to Maturity; PTL- productive tillers, Head Blast (HB), (LDG)- lodging, (PH)- Plant Height; Finger length (FL); Finger Weight per plant (FW), Finger per main ear (FPME) and Yield Kilogram per hectare (YLDkgha)

\section{Agronomic performance}

Combined mean grain yield and other agronomic traits are presented in Table 2. Adis-01 variety was recorded medium days to heading, days to maturity, and plant height, productive tillers and finger per main ear indicated that, the possibility to resist against lodging problems and also it recorded the highest grain yield. In the other hand, Diga variety was recorded medium days to maturity, plant height, and finger weight but it recorded the lowest days to heading, and susceptible to lodging problem.

Table 2: Combined mean grain yield and other agronomic performances of finger millet varieties evaluated.

\begin{tabular}{ccccccccccc}
\hline Varieties & DH & DM & PH & FL & PT & FPME & FW & HB & LDG & YLDkgha \\
\hline Adis-01 & $78.7 \mathrm{~d}$ & $131.8 \mathrm{~b}$ & $66.1 \mathrm{~b}$ & $4.5 \mathrm{ab}$ & $5.6 \mathrm{~b}$ & $5.9 \mathrm{~b}$ & $14.3 \mathrm{ab}$ & $1.5 \mathrm{~cd}$ & $2.1 \mathrm{~cd}$ & $3424.1 \mathrm{a}$ \\
Bareda & $87.1 \mathrm{a}$ & $127.8 \mathrm{c}$ & $62.4 \mathrm{~b}$ & $4.3 \mathrm{abc}$ & $7.5 \mathrm{a}$ & $5.9 \mathrm{~b}$ & $10.8 \mathrm{~b}$ & $3.0 \mathrm{ab}$ & $2.5 \mathrm{ab}$ & $1553.8 \mathrm{e}$ \\
Boneya & $74.8 \mathrm{~g}$ & $131.4 \mathrm{~b}$ & $76.4 \mathrm{a}$ & $4.8 \mathrm{a}$ & $5.8 \mathrm{~b}$ & $6.0 \mathrm{~b}$ & $16.8 \mathrm{a}$ & $1.7 \mathrm{c}$ & $2.0 \mathrm{~cd}$ & $2991 \mathrm{~b}$ \\
Diga & $74.9 \mathrm{~g}$ & $131.6 \mathrm{~b}$ & $61.4 \mathrm{~b}$ & $4.0 \mathrm{bc}$ & $7.4 \mathrm{a}$ & $5.8 \mathrm{bc}$ & $11.1 \mathrm{~b}$ & $3.1 \mathrm{a}$ & $2.7 \mathrm{a}$ & $2116.5 \mathrm{~d}$ \\
Gudetu & $76.4 \mathrm{f}$ & $128.6 \mathrm{c}$ & $58.9 \mathrm{~b}$ & $3.9 \mathrm{bc}$ & $5.1 \mathrm{~b}$ & $6.3 \mathrm{~b}$ & $14.2 \mathrm{ab}$ & $1.8 \mathrm{c}$ & $1.5 \mathrm{e}$ & $2909.5 \mathrm{bc}$ \\
Local & $79.7 \mathrm{c}$ & $131.7 \mathrm{~b}$ & $65.6 \mathrm{~b}$ & $3.7 \mathrm{c}$ & $5.2 \mathrm{~b}$ & $5.1 \mathrm{~cd}$ & $12.7 \mathrm{~b}$ & $1.2 \mathrm{~d}$ & $2.3 \mathrm{bc}$ & $2422.3 \mathrm{c}$ \\
Urji & $77.7 \mathrm{e}$ & $132.5 \mathrm{~b}$ & $60.5 \mathrm{~b}$ & $4.1 \mathrm{abc}$ & $7.3 \mathrm{a}$ & $7.2 \mathrm{a}$ & $10.3 \mathrm{~b}$ & $2.7 \mathrm{~b}$ & $2.7 \mathrm{a}$ & $1460.6 \mathrm{e}$ \\
Wama & $80.7 \mathrm{~b}$ & $135.8 \mathrm{a}$ & $64.9 \mathrm{~b}$ & $4.0 \mathrm{bc}$ & $5.9 \mathrm{~b}$ & $4.9 \mathrm{~d}$ & $17.1 \mathrm{a}$ & $1.5 \mathrm{c}$ & $1.8 \mathrm{de}$ & $2163.4 \mathrm{~d}$ \\
\hline Mean & 78.74 & 131.4 & 64.52 & 4.174 & 6.252 & 5.88 & 13.41 & 2.055 & 2.198 & 2418 \\
R & 0.985 & 0.97 & 0.757 & 0.901 & 0.907 & 0.781 & 0.892 & 0.871 & 0.778 & 0.97 \\
CV\% & 1.38 & 1.254 & 14.44 & 22.42 & 18.44 & 15.57 & 37.92 & 17.99 & 22.31 & 10.37 \\
LSD 5\% & 0.89 & 1.34 & 7.6 & 0.76 & 0.94 & 0.75 & 4.2 & 0.3 & 0.4 & 204.6 \\
F-test & $* *$ & $* *$ & $* *$ & $*$ & $* *$ & $* *$ & $*$ & $* *$ & $* *$ & $* *$
\end{tabular}

Key: $* * *$, significant at $5 \%$ and $1 \%$ respectively, $\mathrm{R}^{2}-\mathrm{R}$ - square, $\mathrm{CV}$-coefficient of variation, LSD-least significance differences, DH- Days to Heading; DM- Days to Maturity; PTL- productive tillers, Head Blast (HB), (LDG)- lodging, (PH)- Plant Height; Finger length (FL); Finger Weight per plant (FW), Finger per main ear (FPME) and Yield Kilogram per hectare (YLDkgha)

Disease reaction with finger millet varieties across environments

Disease reaction: the result revealed that Adis-01, Boneya, Gdetu, Urji and Wama varieties are better tolerance to economically important head blast disease but Diga and Bareda varieties are less tolerance to head blast disease (Table3) 
Table 3: Disease reactions for yield and yield related traits of the evaluated improved finger millet varieties

\begin{tabular}{cc}
\hline Varieties & Head Blast \\
\hline Adis-01 & $1.5 \mathrm{~cd}$ \\
Bareda & $3.0 \mathrm{ab}$ \\
Boneya & $1.7 \mathrm{c}$ \\
Diga & $3.1 \mathrm{a}$ \\
Gudetu & $1.8 \mathrm{c}$ \\
Local & $1.2 \mathrm{~d}$ \\
Urji & $2.7 \mathrm{~b}$ \\
Wama & $1.5 \mathrm{c}$ \\
\hline Mean & 2.055 \\
Cruare (\%) & 87.1 \\
LSD 5\% & 17.99 \\
F-test & 0.3 \\
\hline
\end{tabular}

Key: 1-5 scale scoring was used for disease reaction where $1=$ resistant, $5=$ susceptible $C V=$ coefficient of variation, LSD =least significant different

\section{Additive Main Effects and Multiple Interaction (AMMI) model}

The mean squares for all varieties evaluated under different environmental condition for grain yield are presented in Table4. The result indicated that differences among all varieties were significant $(\mathrm{P} \leq 0.01)$. Variation due to genotypes by environments interaction was significant for the studied traits, indicated that genotypes differ genetically in their response to different environment. The genotypes by environments interaction was significant effect on the grain yield, which explained $23.44 \%$ of the total variation whiles the genotypes, contributed $32.67 \%$ of the variation. However, large portion $(40.84 \%)$ of the total variation was attributed to the environmental effect. Table 4 Additive main effect and multiplicative interaction analysis of variances (AMMI) for grain yield of eight finger millet varieties

\begin{tabular}{ccccc}
\hline Source & D.F. & S.S. & EX.SS\% & M.S. \\
\hline Total & 95 & 128353731 & 100 & 1351092 \\
Treatments & 31 & 124429241 & 96.94 & $4013846^{* *}$ \\
Genotypes & 7 & 41928507 & 32.67 & $5989787^{* *}$ \\
Environments & 3 & 52414333 & 40.84 & $17471444^{* *}$ \\
Block & 8 & 375731 & 0.29 & $46966^{\text {ns }}$ \\
Interactions (GxE) & 21 & 30086401 & 23.44 & $1432686^{* *}$ \\
IPCA 1 & 9 & 23083507 & 17.98 & $2564834^{* *}$ \\
IPCA 2 & 7 & 6527931 & 5.09 & $932562^{* *}$ \\
Residuals & 5 & 474964 & 0.37 & 94993 \\
Error & 56 & 3548759 & & 63371
\end{tabular}

Key: DF = degree of freedom, $\mathrm{SS}=$ sum of squares, $\mathrm{MS}=$ mean squares, IPCA = Interaction Principal Component Axis, $* *=$ highly significant, ${ }^{\mathrm{ns}}=$ non-significant, EX. SS\%-Explained Sum of square

Significant percentage of genotypes by environments interaction was explained by IPCA-1 (17.98\%) followed by IPCA2 (5.09\%).Accordingly, Gauch and Zobel (1996) recommended that the most accurate model for AMMI can be predicted by using the first two PCAs. The genotypes by environments interaction components were smaller relative than to the genotypic components and if they were related to predictable environment factor (such as geographic areas, major pest problems,) the breeder searches for a genotypes to must the specific requirements of that environment while the interaction is small and unpredictable (micro climatic or yearly variation in weather and management practices) the breeder searches for a genotypes that has general adaptability and unversed performance over the range environments.

Comparison plot for genotypes based on the concentric circle

Figure 1: shows the comparison plot for variety, and an ideal variety is one which is near or at the center of the concentric circle. Accordingly, the plot reflected that Adis-01 and Boneya are the most ideal varieties as shown by their position. It also reflects that, these varieties have high mean grain yield and more stable. 


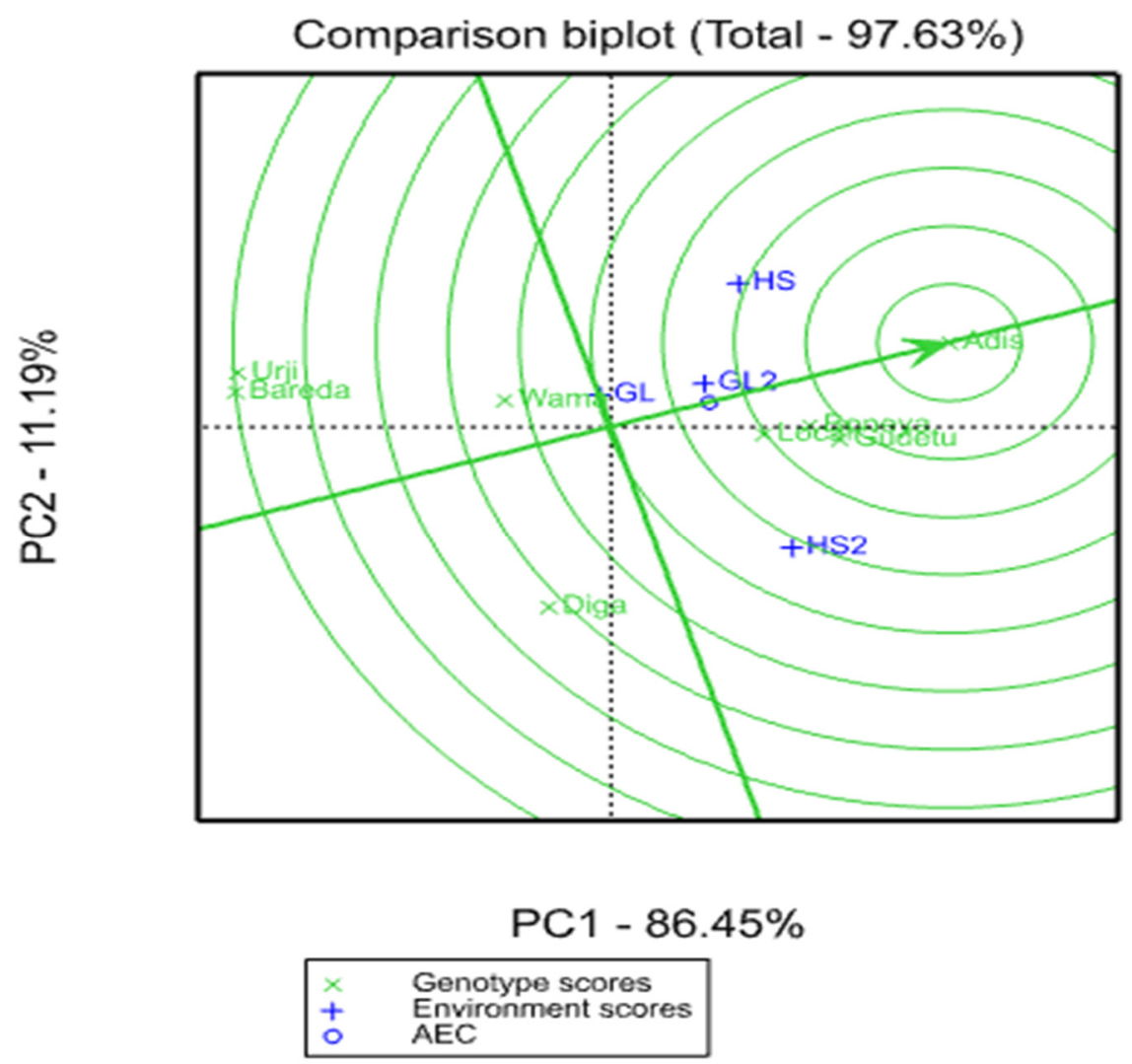

Figure 1: GGE bi-plot based on genotype-focused scaling for comparison of genotypes for their yield potential and stability

\section{Conclusions and Recommendations}

Combined analysis of variance (ANOVA) result revealed significant difference of grain yield and most of yield contributing traits among evaluated finger millet varieties across locations, years and the interactions. This indicated that, the location and fluctuation of weather condition over the cropping season had affected performance of varieties. Although the GEI of grain yield partitioned in to different IPCAs using AMMI model analysis, the first principal component axis for interaction alone explains most of the interaction sum of squares. The sign and magnitude of IPCA scores showed the relative contribution of each genotype and environment for the genotype and environment interactions. This helps to summarize the pattern and magnitude of GEI and main effects that reveal clear insight into the adaptation of genotypes to environments. This shows that, Adis -01 and Boneya varieties are fewer contributors to the interaction effect and have consistent performances across locations. Therefore, Adis- 01 and Boneya were identified as the best varieties in terms of yielding ability and stability, tolerant to diseases and better agronomic performance.

\section{Acknowledgment}

The authors greatly acknowledged Oromia Agricultural Research Institute (IQQO) for financial support. HaroSebu Agricultural Research Center staff members are warmly acknowledged for technical and administrative support. Specifically, cereal research team significantly thankful for their technical support in all rounds, Bako agricultural research center is also acknowledged for the provision of test materials.

\section{REFERENCES}

Adugna A, Tesso T, Degu E, Tadesse T, Merga F, Legesse W, Tirfessa A, Kidane H, Wole A \&Daba C (2011) Genotype-by-Environment Interaction and Yield Stability Analysis in Finger Millet (Eleusine coracana L. Gaertn) in Ethiopia. American Journal of Plant Sciences 2: 408-415.

Ariyo, J. (1989). Factor analysis of pod yield in Okra (Abelmoschusesculentus).Theoretical and Applied Genetics 64: 82-85.

CSA (2017), The Federal Democratic Republic of Ethiopia, Central Statistical Agency agricultural sample survey 2016/2017 (2009 E.C) volume I report on area and production of major crops (private peasant holdings, Meher season). Statistical Bulletin no.584, Addis Ababa, Ethiopia, pp. 118

Damar, W. K., Russom, Z., Garba, A.A., Ibrahim, S. A. \& Haggai, P. T (2016) Yield Response of Finger Millet 
(Eleusine Coracana (L) Gaertn) To Transplanting Date, Intra Row Spacing and Poultry Manure In Bauchi, Nigeria. International Research Journal of Natural and Applied Sciences Vol. 3, Issue 5.

Degu, E., Adugna, A., Tadesse, T. and Tesso, T. (2009). Genetic resources, breeding and production of millets in Ethiopia, In new approaches to plant breeding of orphan crops in Africa. Proceedings of an International Conference, Bern Switzerland, 19-21 September, 2007.

Eberhart, S.A. and Russell, W.A. (1966). Stability parameters for comparing varieties, Crop Science 6: 36-40.

Farshadfar, E. and Sutka, J. (2006). Biplot analysis of genotype-environment interaction in durum wheat using the AMMI model. Acta Agronomy Hung. 54: 459-467.

Flores, F.; M.T. Moreno and J.I. Cubero (1998) A comparison of uni-variate and multivariate methods to analysis $\mathrm{G} \times \mathrm{E}$ interaction Field - Crops Res. 56: 271- 286.

Gauch, H. G. and Zobel, R.W. (1996). AMMI analysis of yield trials. In: Genotype by environment interaction. pp. 85-122 (Kang, M. and Gauch, H. eds.). Boca Raton. CRC press, New York.

Gauch, H.G., Piepho, H.P. and Annicchiarico, P. (2008). Statistical analysis of yield trials by AMMI and GGE: Further considerations. Crop Science 48:866-889.165

Girma T, (1999). Modeling Genotype by environment interaction: A Review of procedures In: Proceeding of the Eight Annual Conference of the Crop Science Society of Ethiopia, pp 147 - 158, Addis Ababa, and Ethiopia.

Mustapha, A, A.; F.A. Showemino and A. Aminu - kano (2001). Yield stability analysis of promising maize cultivars in Nigeria. J. Arid Agric 11: 1 -4.

Okalebo JR, Jutto PM \& Gathera KW (1991) Effect of form and method of phosphate fertilizer application on maize, sorghum and millet growth in semi-arid environment of Kenya. II. Effect of bulrush and finger millet. East African Forestry Journal 55: 239-248.

SAS Institute Inc. (2008). Statistical analysis Software version 9.2, Cary, NC: SAS Institute Science 6: 36-40.

Showemimo, F.A., C.A. Echekwu and M.Y. Yeye (2000) Genotype $\times$ environment interaction in sorghum trials and their implication for future variety evaluation in maize growing areas of northern Nigeria the Plt. Scientist 1: $24-31$

VSN International, (2012) "Gen Stat for Windows 15th Edition VSN International, Hemel Hempstead, UK" Available: www.genStat.co.uk

Worku, A., Henry, M., Zewotir, T. and Taye, G. (2013). Additive main effects and multiplicative interactions model (AMMI) and genotype main effect and genotype by environment interaction (GGE) biplot analysis of multi-environmental wheat variety trials. African Journal of Agricultural Research 8(12):1033-1040.

Yan, W., Hunt, L.A., Sheng, Q., Szlavnics, Z. (2000). Cultivar evaluation and mega environment investigation based on the GGE bi-plot Crop Science.40:597-605

Yuksel Kaya, Cetin Palta, SeyfiTaner (2002). Additive main effects and multiplicative interactions analysis of yield performances in bread wheat genotypes across environments. Turkish Journal Agriculture and Forestry 26: $275-279$ 